\title{
Aprendizagem Colaborativa e Violência Entre Jogadores de League of Legends
}

\section{Collaborative Learning and Violence Amongst League of Legends Players}

\author{
Jonathan Bernardes Golart \\ Universidade Federal do Rio Grande do Sul \\ Renata Fischer da Silveira Kroeff \\ Universidade Federal do Rio Grande do Sul \\ Póti Quartiero Gavillon \\ Universidade Federal do Rio Grande do Sul
}

\begin{abstract}
Resumo: Compreendemos os videogames como objetos culturais e protótipos de novos modos de alfabetização. Neste trabalho, discutimos o protagonismo de jogadores na produção de conhecimento dentro dos espaços de afinidade que circundam os jogos digitais. Foi realizada uma entrevista semi-estruturada com um jogador profissional de League of Legends, assim como uma análise de postagens de jogadores no fórum online Reddit, buscando compreender a relação dos jogadores em comunidade. A análise indica que os jogos propiciam a construção de espaços de aprendizagem colaborativa e que mesmo que o jogo tenha conteúdo que representa violência, ou que os jogadores possam ser violentos nas competições dentro do jogo, não há indício de que o mesmo produza violência em outros espaços.
\end{abstract}

Palavras-chave: Espaços de afinidade, Cultura participativa, League of Legends, Violência, Aprendizagem.

\begin{abstract}
We understand videogames as cultural objects and prototypes of new ways of literacy. In this work, we discuss the protagonism of players in the production of knowledge within the spaces of affinity that surround digital games. A semi-structured interview was conducted with a professional League of Legends player, as well as an analysis of player postings in the online forum Reddit, seeking to understand the players' relationship in community. The analysis indicates that the games facilitate the construction of spaces of collaborative learning and that even if the game has content that represents violence, or if players can be violent in the in-game competitions, there is no indication that it produces violence in other spaces.
\end{abstract}

Keywords: Affinity spaces, Participatory culture, League of Legends, Violence, Learning. 


\section{Introdução}

A proliferação das mídias digitais no cotidiano de crianças, jovens e adultos, se efetiva com a multiplicação dos tipos de dispositivos e com o acesso à diversidade de aplicativos que permitem a conexão instantânea entre usuários, possibilitando que os mesmos dediquem mais tempo à participação em espaços compartilhados online. No presente artigo, abordamos, em especial, dois exemplos de tais espaços: um jogo digital online multijogador e um fórum de discussão online destinado ao compartilhamento de informações entre seus jogadores. Analisamos as práticas sociais produzidas em torno das experiências dos jogadores com o jogo League of Legends (RIOT GAMES, 2009) e discutimos possíveis conexões com práticas em contextos externos as partidas de jogo.

Não consideramos os jogos digitais apenas como uma tecnologia estática (a especificidade do código do jogo, por exemplo) - embora a programação seja um símbolo desse segmento e seu crescimento -, mas, principalmente, como uma prática cultural - a ação de jogar (SQUIRE, 2011). Tal proposta, compreende não apenas o estudo das configurações digitais do design do jogo, mas também a interação entre os sujeitos e o espaço de jogo, assim como, a relação dos jogadores entre si.

Precisamos, então, fazer uma distinção entre a ação de jogar e o projeto do jogo. Os desenvolvedores de jogos produzem as condições necessárias para que a ação de jogar aconteça, sustentando uma variedade de formas possíveis. Organizam espaços de possibilidade onde a experiência de jogo acontece, ou seja, as regras do jogo estabelecem as condições para a experiência de jogo, mas não uma determinação direta de como o jogador irá desenvolver sua performance no jogo (GAVILLON \& MARASCHIN, 2015). Uma relação de co-autoria acontece a cada partida como resultado da interação entre o design do jogo (ação do programador) e a performance de jogo (ação do jogador). Squire (2006) corrobora essa ideia a partir do conceito de experiência projetada, isto é, os jogos digitais possibilitam, a partir da maneira como foram projetados, múltiplas formas de explorá-los.

Para Salen (2004), os espaços de possibilidade são construídos e fornecem o contexto, gerando sentido para o ato de jogar. Esses sentidos são posteriormente compartilhados pela comunidade de jogadores na forma de relatos de suas performances de jogo. Os relatos, por sua vez, representam o desejo dos jogadores em poder ampliar as formas de interação com o jogo. Isto pode ser observado, por exemplo, a partir da comunicação entre desenvolvedores e jogadores, em espaços externos ao jogo - como os fóruns de discussão online - nos quais as experiências dos jogadores muitas vezes são consideradas pelos desenvolvedores para a realização de atualizações do jogo.

No campo de estudos dos videogames, também são recorrentes as discussões sobre o processo imersivo de conhecimento (BARTLE, 2010). Gee (2003), ao aventurar-se no mundo dos jogos digitais como jogador iniciante, notou que os modos clássicos de aprender não funcionavam para que ele conseguisse efetuar uma boa performance no jogo. Era necessário um letramento específico relacionado a forma de organização desses espaços digitais de interação. Para o autor, tal necessidade de aprendizagem e o desafio que ela envolve é, em grande parte, aquilo que torna os videogames interessantes e divertidos. Para De Paula (2010) um letramento ligado às formas de aprender corresponde às formas de entender e criar significados e os jogos digitais exigem o desenvolvimento de competências para que se participe ativamente e plenamente de seu domínio semiótico. Nessa perspectiva, entendemos que pesquisadores imersos (isto é, pesquisadores-jogadores) têm experiências interessantes para avaliar os processos que aí se desenvolvem, visto que os jogos envolvem não apenas conhecimentos declarativos (sabersobre), mas também extensas redes de conhecimentos operativos (saber-fazer) relacionados à interatividade proporcionada por este tipo de mídia e a variedade incalculável de possibilidades de ação que os jogadores podem efetuar e que se evidenciam através de performances singulares a cada partida. 
O avanço nos estudos dos videogames requer uma compreensão dos modos pelos quais os jogadores habitam determinados mundos virtuais, e em que medida experienciam estes como significativos, pois o surgimento de uma comunidade em torno de um jogo concede a este um caráter cultural (STEINKUEHLER, 2006). Considerando os videogames como objetos culturais, um fator de interesse da presente pesquisa refere-se aos discursos que associam a prática de jogar videogame à suposta produção de condutas violentas. A discrepância entre a experiência como jogadores de jogos digitais e alguns dos pressupostos presentes nestes discursos fez com que buscássemos estudar a cultura dos videogames segundo a perspectiva dos game studies, principalmente, das publicações de Kurt Squire (2006; 2011), Jenkins (2006; 2009) e James Paul Gee (2003; 2010); e de algumas das principais produções brasileiras sobre o assunto (ALVES, 2004; DE PAULA, 2010; BAUM 2012; MARASCHIN \& BAUM, 2011). Esses autores têm em comum a proposta de estudar os games a partir de uma perspectiva imersiva na cultura dos jogos, ou seja, de uma valorização da experiência do jogador.

Apresentamos, a seguir, uma breve descrição do jogo League of Legends e sua proposta de jogabilidade. A fim de analisar as interações entre jogadores em torno da experiência com o jogo, a estratégia metodológica utilizada compreendeu a análise de postagens no fórum de discussão online Reddit e uma entrevista semi-estruturada realizada com um jogador profissional de League of Legends, que apresenta intensa participação em espaços online de discussão entre jogadores. A partir dos registros no fórum e da entrevista, discutimos algumas implicações do espaço de discussão online para os jogadores e sua relação com o jogo League of Legends. Neste percurso, são descritos conceitos que se referem a aspectos participativos da comunidade de jogadores $e$ aos processos de aprendizagem entre eles. Discutimos as práticas realizadas por jogadores em torno da cultura dos videogames, acreditando que as mesmas fornecem subsídios para que usuários sejam reconhecidos como produtores de conhecimento. Por fim, discutimos algumas proposições a respeito da suposta relação entre videogames e comportamentos.

\section{Jogo League of Legends}

O jogo League of Legends será também chamado nesse artigo de "LoL", denominação frequentemente utilizada pelos jogadores ao se referirem ao jogo. Atualmente, o LoL é o jogo online mais jogado no mundo, com 32 milhões de usuários ativos diariamente (RIOT GAMES, 2014), chegando a 100 milhões de jogadores ativos mensalmente (VOLK, 2016) e possuindo a maior comunidade de discussão online de jogos. São mais de 25 milhões de usuários em diversas redes sociais - com mais de 750 mil comentários sobre o jogo por semana (RIOT GAMES, 2013) -, sendo 700 mil pessoas cadastradas apenas no fórum não oficial www.reddit.com/r/leagueoflegends (RIOT GAMES, 2013).

O gênero Multiplayer Online Battle Arena (MOBA) - do qual faz parte o jogo League of Legends - surge com a possibilidade dos jogadores customizarem personagens e criarem cenários novos em jogos já existentes, como Warcraft III (BLIZZARD, 2002) e Starcraft (BLIZZARD,1998), utilizando ferramentas disponibilizadas pelos desenvolvedores. A partir destes processos de modificação foi desenvolvido em 2003 o jogo Defense of the Ancients (DOTA) - título que dá origem ao aspecto competitivo das arenas de batalha - baseado no jogo Warcraft III (BLIZZARD, 2002). A partir da popularização do DOTA (EUL, 2003), foram desenvolvidos outros MOBAs, dentre eles o League of Legends.

Ao preparar uma partida de LoL, pode-se selecionar inicialmente a configuração do mapa em que se deseja jogar. O mapa principal, summoners rift (fenda dos invocadores, tradução nossa, figura 1), consiste em um ambiente de florestas, repleto de monstros, que é atravessado longitudinalmente por três rotas principais. Essas rotas partem da base do time do jogador para um mesmo destino: a estrutura adversária central, localizada no extremo oposto do mapa, dentro da base inimiga. Cinco jogadores em cada time irão se dividir entre essas três rotas principais (superior, central e inferior), a fim de percorrer o mapa e destruir as estruturas adversárias. 


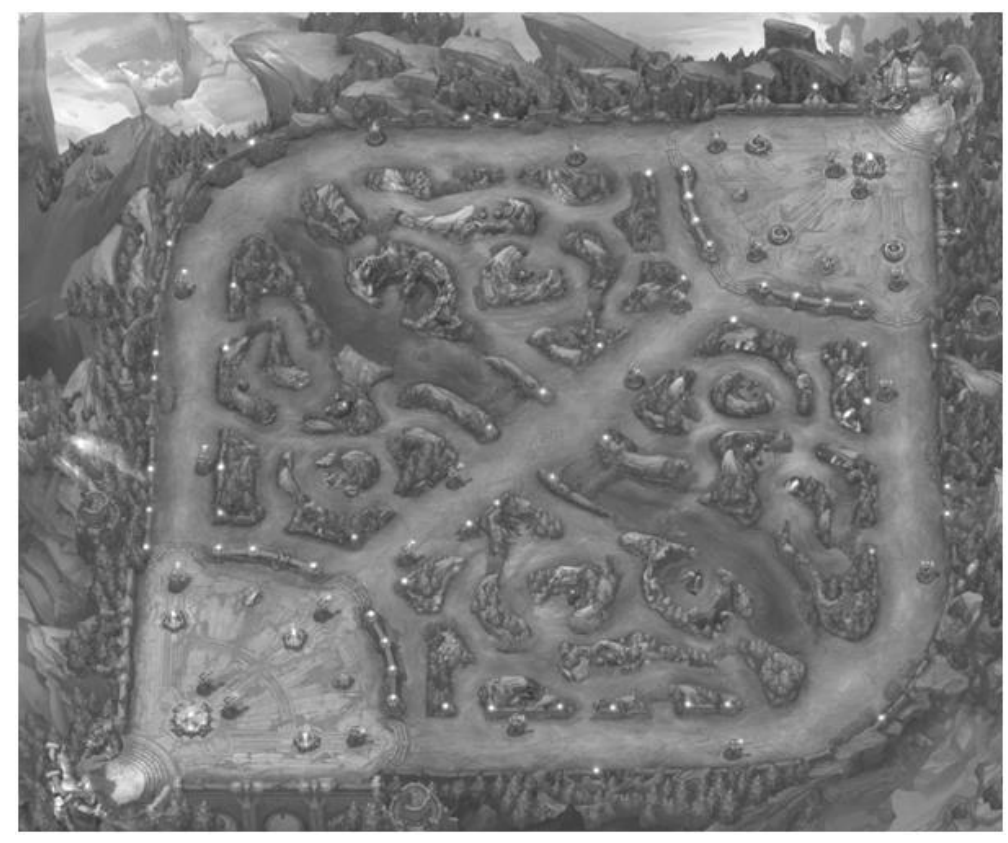

Figura 1 - Vista aérea do mapa Summoners Rift

Em seguida, decide-se o modo de jogo: amistoso ou competitivo. O primeiro é organizado para ser um modo de jogo casual, no qual o pareamento dos jogadores (definição dos integrantes de cada equipe) independe de sua habilidade ou experiência prévia, sendo um modo de jogo comum para convidar amigos a conhecer o jogo e também para experimentar novas estratégias. O modo competitivo, por sua vez, fornece pontuações aos jogadores, aumentando seu ranqueamento ${ }^{1}$ dentro do jogo e dando-Ihes direito a recompensas - como customizações e emblemas exclusivos - a partir do acúmulo de pontos em períodos de tempo determinados (temporadas do jogo). Por isso, é considerado um modo de jogo no qual se deve escolher a rota com a qual o jogador esteja mais familiarizado e os melhores personagens para ela. Ao entrar em uma partida, o jogador é pareado com outros nove jogadores de nível semelhante, sendo todos divididos em duas equipes, cada uma composta por cinco integrantes. A partir de então, os jogadores escolhem seus personagens (chamados no jogo de campeões) - que possuem habilidades variadas -, enquanto abre-se uma caixa de diálogo, por meio da qual a equipe pode decidir em conjunto quem ocupará cada posição dentro do mapa da arena de jogo de acordo com seu desejo e as características do personagem escolhido. Após, na tela de carregamento, o jogador pode ver a posição de seus colegas de equipe no ranking, bem como a personalização ${ }^{2}$ comprada para cada campeão.

Durante as partidas, cada equipe é auxiliada por creeps - unidades de inteligência artificial que são pequenos personagens que andam em grupos e que se dirigem à base adversária ajudando a equipe correspondente a lutar, a derrubar torres de defesa e que, quando derrotados, recompensam os adversários com ouro. Isso é importante, pois durante a partida cada jogador pode trocar o ouro recebido por itens para melhorar o seu personagem. A partida termina quando a base de alguma das equipes é destruída. Ao final, o jogador tem a oportunidade de ver as estatísticas de cada personagem ao longo do jogo, bem como conversar com seus companheiros de equipe e os adversários sobre a partida.

\footnotetext{
${ }^{1}$ Classificação em ordem: Desafiante, mestre, diamante, platina, ouro, prata e bronze.

2 League of Legends é totalmente gratuito, entretanto, na loja há opções para personalizar o seu campeão favorito
} esteticamente, mudando suas roupas e sua temática. 


\section{Rota Metodológica}

Diversos conteúdos em espaços de discussão online voltados ao compartilhamento de experiências em relação aos videogames são produzidos, diariamente, na internet. Jogadores se dedicam a estudar jogos específicos e a compartilhar conhecimentos relacionados a saber jogálos (know-how). A fim de acompanhar esse processo de aprendizagens compartilhadas, optamos por uma estratégia qualitativa de análise, buscando reconhecer a experiência singular de cada jogador em sua relação com a comunidade. Neste sentido, alguns operadores conceituais propostos pelos game studies, oportunizaram que essas experiências pudessem ter sua especificidade reconhecida, uma vez que compreendem a legitimidade do exercício de diversos papéis dentro da cultura dos jogos e demonstram o caráter potente e múltiplo desses grupos.

Analisamos discussões relacionadas ao jogo LoL no fórum Reddit ${ }^{3}$ e realizamos uma entrevista semiestruturada com um jogador profissional de LoL, que será referenciado aqui pelas iniciais M.E.G. A escolha do jogador considerou a experiência do mesmo no cenário nacional dos jogos competitivos, a partir de sua atuação profissional em campeonatos de LoL, e também sua frequente participação em discussões online com a comunidade de jogadores. M.E.G. possui uma das cinco páginas de jogadores profissionais mais curtidas no Facebook.

\section{Espaços de Afinidade}

De acordo com Squire (2011) não podemos abordar os videogames considerando somente o jogo como um tipo de mídia ou tecnologia, também precisamos incluir as comunidades participativas de jogadores que, frequentemente, acompanham a experiência com os games e constituem espaços importantes de aprendizagem. Baseado nos estudos de James Paul Gee (2003), o autor apresenta o termo espaços de afinidade para se referir a grupos que se formam por associação voluntária, com o objetivo de compartilhar conhecimento sobre determinado assunto (SQUIRE, 2011). Dessa forma, os espaços de afinidade podem ser constituídos em torno de diversos temas - não somente dos jogos digitais - e se manifestarem de formas diferentes na cultura: amigos que se reúnem para discutir futebol; grupos de compartilhamento de receitas culinárias; um professor que instiga alunos a criarem um grupo de literatura, configuram alguns exemplos. De forma geral, ao descrevermos estes grupos em torno da experiência nos jogos digitais, não estamos colocando a mídia digital em primeiro lugar. O que nos interessa é a capacidade de coletivos mobilizarem indivíduos e tecnologias para compartilharem conhecimentos e aprenderem um tema de interesse comum.

Gee (2010) apresenta algumas características que definem tais espaços de afinidade. Entre elas o fato de que, inicialmente, a afinidade nestes espaços se daria pelo conteúdo das discussões e não pelas características pessoais dos participantes. Por isso, não haveria, a priori, limitações para a participação relacionadas a sexo, a raça, a nacionalidade ou a religião, embora as mesmas possam se fazer presentes em alguns grupos. Muitas vezes os participantes se mantêm anônimos, apresentando-se por meio de apelidos ou nomes de avatares. A figura 2, por exemplo, mostra um jogador com o emblema do campeão Thresh que tem dificuldades para utilizar este personagem efetivamente, pedindo auxílio para jogadores mais experientes. Dois jogadores que possuem o mesmo emblema buscam dar dicas: um deles sobre os itens para melhorar o personagem no jogo e o outro visando explicitar a forma como o campeão deve atuar na rota mais adequada para jogar com ele.

\footnotetext{
${ }^{3}$ As imagens foram acessadas em outubro e novembro de 2015. www.reddit.com/r/leagueoflegends
} 


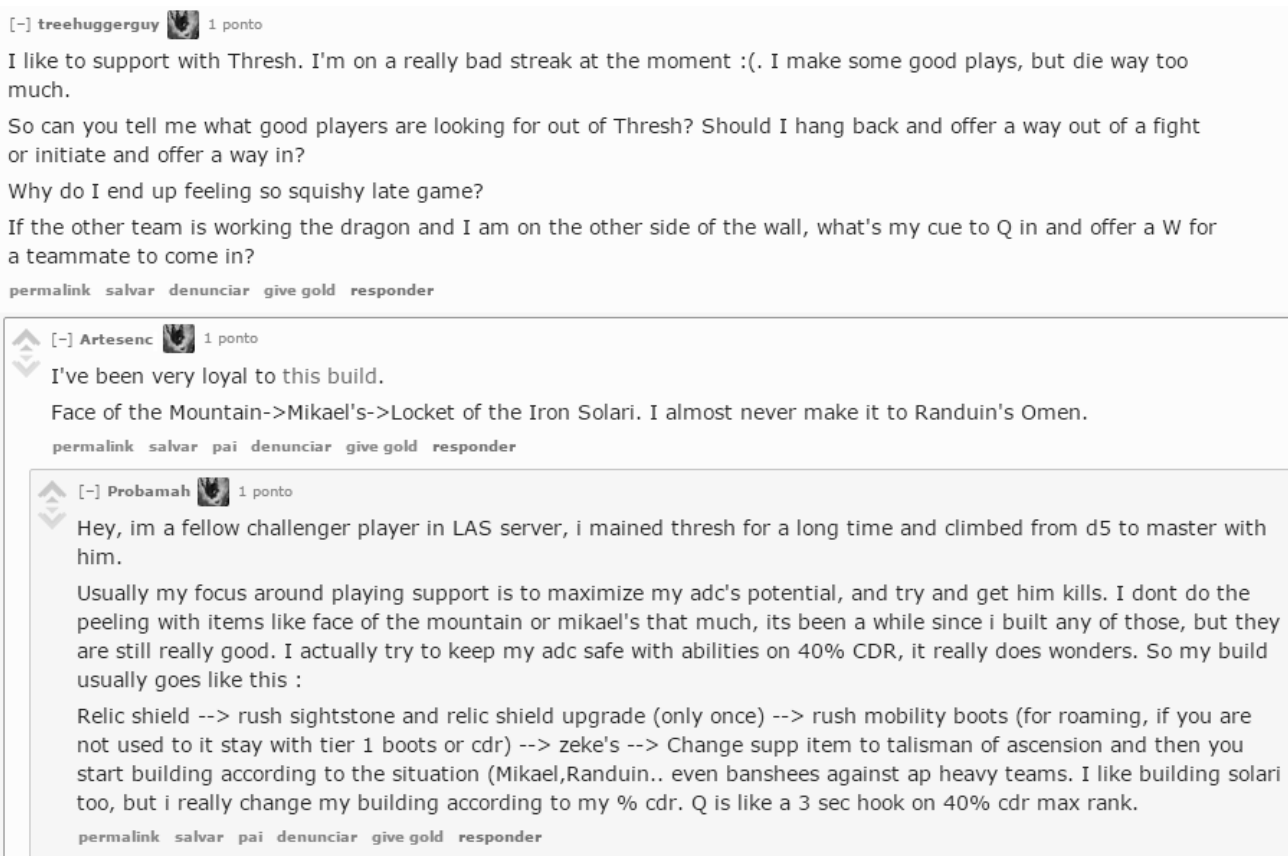

Figura 2 - jogadores novatos e experientes compartilham o mesmo espaço ${ }^{4}$

Para Squire (2011) esses espaços geram oportunidades nas quais jogadores menos experientes podem aprender com outros mais experientes. Gee (2003) considera esta característica importante nos espaços de afinidade, pois o fato de tanto os novatos quanto os melhores jogadores partilharem o mesmo espaço, encoraja formas diferenciadas de participação. A figura acima mostra que o jogador que oferece auxílio com o campeão Thresh está no nível mais alto, "challenger", e que ele se dispõe a dar dicas para outro membro desse espaço sobre como melhorar sua performance de jogo com aquele campeão. Considerando que jogadores podem ter saberes diferentes sobre o jogo - alguns, por exemplo, podem ser mais experientes em jogar com alguns campeões e não com outros -, existe a possibilidade de flutuação das posições de liderança. Assim, a liderança é permeável, sem hierarquias rígidas, podendo assumir diferentes configurações.

\footnotetext{
${ }^{4}$ treehuggerguy

Eu gosto de jogar como suporte com Thresh. Eu estou em uma série de jogos muito ruim no momento :(. Eu faço algumas boas jogadas, mas morro de forma demasiada.

Então, vocês podem me dizer o que bons jogadores estão procurando no Thresh? Devo ficar para trás e oferecer uma saída para uma luta ou iniciar e oferecer um caminho de entrada?

Por que eu acabo me sentindo tão frágil no fim do jogo?

Se a outra equipe está trabalhando o dragão e estou do outro lado do muro, o que é a minha deixa para Q e oferecer um W para um companheiro de equipe para entrar?

Artesenc

Eu tenho sido muito fiel a esta itemização.

Face da montanha-> Cadinho de Mikael-> Medalhão do Solari de ferro. Eu quase nunca chego em Presságio de Randuin. Probamah

Oi, sou um jogador desafiante no servidor LAS, jogando principalmente Thresh por um longo tempo e subi de Diamante 5 para mestre com ele.

Normalmente, o meu foco em torno de jogar suporte é para maximizar o potencial do meu atirador, e tentar ajudá-lo a matar. Eu não faço o peeling com itens como face da montanha ou cadinho de mikael muito, faz um tempo desde que eu construí algum deles, mas eles ainda são muito bons. Na verdade, eu tento manter meu atirador seguro com habilidades em $40 \%$ redução de tempo de recarga, isso realmente faz maravilhas. Assim, a minha itemização geralmente é assim Escudo Relicário --> agilizar pedra da visão e o aprimoramento do escudo relicário (apenas uma vez) --> agilizar botas (para roaming, se você não está acostumado ficar com botas nível 1 ou redução do tempo de recarga) --> emissário de zeke --> Trocar item de suporte para talismã da ascensão e então você começar a construir de acordo com a situação (Mikael, Randuin.. mesmo Banshees contra equipes com muito poder de habilidade. Eu gosto de construir Solari também, mas eu realmente mudo minha itemização de acordo com a minha \% de redução de tempo de recarga. Q é como um gancho de 3 segundos em $40 \%$ de redução no ranqueamento máximo.
} 
Há momentos, entretanto, que jogadores novatos podem não se sentir confortáveis para criar novos tópicos para velhas discussões. Em vista disso, há a iniciativa de jogadores experientes ou moderadores dos fóruns de chamar os novatos para a discussão, abrindo tópicos específicos como, por exemplo, o "mega tópico de segunda" do fórum Reddit, que visa oferecer um espaço acolhedor para jogadores iniciantes. A figura 3 mostra exemplos de três edições deste tópico, cada uma possuindo aproximadamente 1.500 comentários, entre questionamentos de novos jogadores e mensagens afirmando a importância dessa iniciativa para auxiliar aqueles que estão começando.

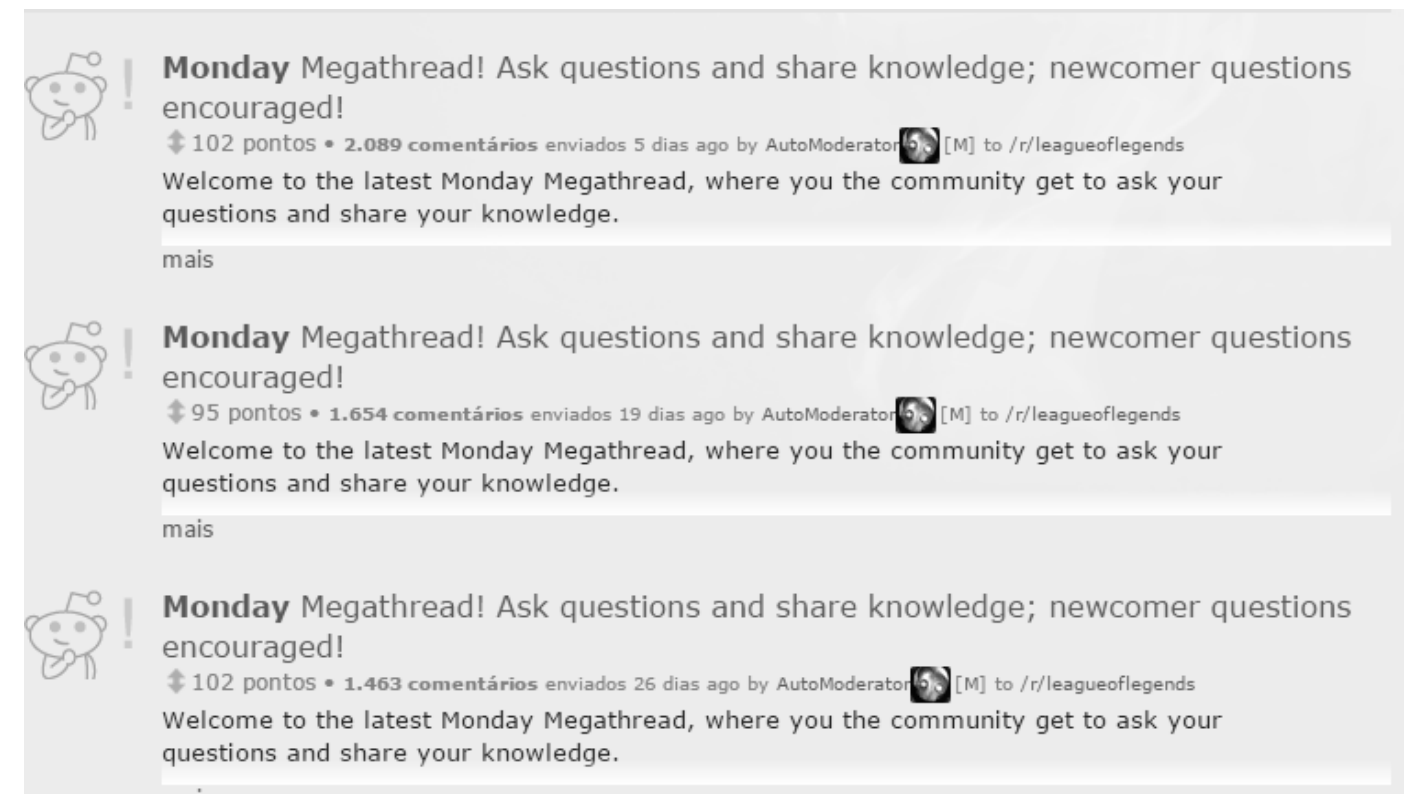

Figura 3 - Exemplo de postagem recorrente no fórum de LoL ${ }^{5}$

Gee (2010) considera importante a abertura do espaço de afinidade para formas de conhecimento disperso, isto é, conhecimentos que não foram originalmente produzidos nele, mas em outros sites, livros ou filmes, entre outros, e que são incorporados na discussão visando aprimorar a relação dos indivíduos com esse conhecimento e suas competências. Na figura 4, 0 jogador "hipstermankey" pede auxílio buscando entender as novidades incorporadas ao jogo nos últimos meses. O jogador "Killua544" apresenta duas fontes externas ao fórum, acrescentando informações importantes para o aprimoramento sobre o tema.

\footnotetext{
${ }^{5}$ Megatópico de Segunda-feira! Faça perguntas e compartilhe conhecimento; questões de recém-chegados encorajadas! Bem-vindo ao mais recente Megatópico de segunda-feira, onde vocês, a comunidade, podem fazer suas perguntas e compartilhar seu conhecimento.
} 
Hipstermankey Silver II 3 pontos 1 dia ago

Ok here is the thing: I really like supporting but I am currently feeling out of touch because I stopped playing some months ago and kind of need to catch up on many things.

Also I think I'm not a bad player but I lack most of the advanced theory of supporting or general playing and I would be interested in some good resourced where I can catch up on all the stuff that is important.

Currently I'm in silver II (just played the promotion games and nothing more) if that is in any way important to the question.

TL;DR: What are the best support-related resources?

permalink salvar denunciar give gold responder

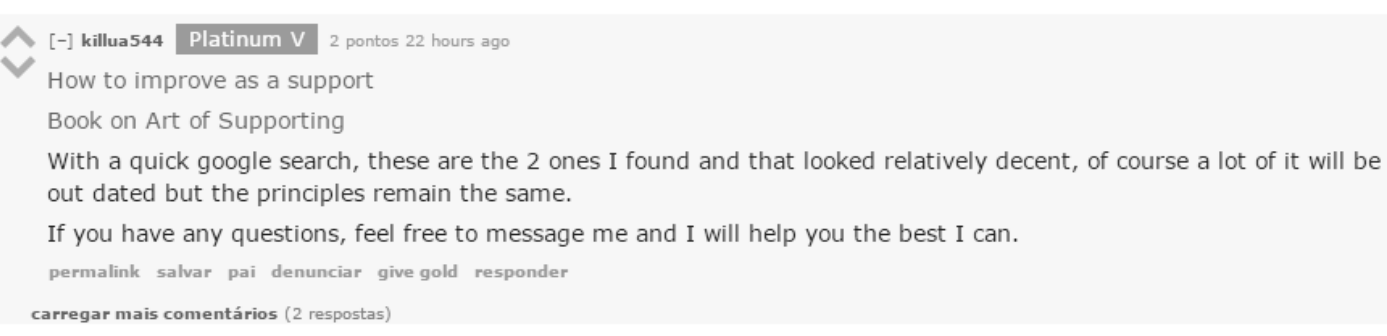

Figura 4 - interação entre novatos e experientes ${ }^{6}$

Nestas comunidades os participantes buscam trabalhar em coletivo, num projeto compartilhado no qual todos podem estar envolvidos. Este é um processo que auxilia a consolidação da confiança entre os pares, sendo a mesma construída ao longo do desenvolvimento dos conteúdos (Squire, 2011). Este acaba tornando-se um princípio bastante presente nos espaços de afinidade auto organizados.

Além disso, Gee (2010) salienta a potência destes espaços como geradores de conteúdo, tanto na relação entre os jogadores, quanto com a indústria de jogos. Entre si, os jogadores criam mapas, ilustrações, histórias. Com base nessas discussões e conteúdos produzidos na comunidade de jogadores, os desenvolvedores do jogo consideram possibilidades de alteração do jogo e, assim, o conteúdo de League of Legends é constantemente transformado com a contribuição dos jogadores.

\section{Cultura Participativa}

Segundo Jenkins (2006), a internet facilita ações coletivas, soluções de problemas e formas de criatividade alternativa. Para o autor, a cultura participativa propiciada pelo caráter interativo da Internet constitui uma mudança no modo como as pessoas se relacionam com os meios de comunicação, alterando os papéis de produtores e consumidores de informação. A participação pode acontecer através da escrita, de vídeos, comentários, sugestões, dicas, histórias. A partir do reconhecimento dos espaços de afinidade relacionados aos jogos, a cultura dos videogames se fortalece, unindo jogadores em torno de projetos, que não necessariamente se limitam ao espaço digital. League of Legends cativa o jogador, estimulando que sua participação não se efetive somente nos espaços online, mas que possa se estender para outros espaços, contemplando outras formas de relação. A transição de um campeonato sem público presente, como o realizado em 2011, para um campeonato com público de quarenta mil espectadores no estádio olímpico de Seul, durante a final de 2014, demonstra que o interesse de interação por

\footnotetext{
${ }^{6}$ Hipstermankey

Ok, é o seguinte: Eu realmente gosto de jogar como suporte, mas atualmente estou sentindo fora de contato, porque eu parei de jogar há alguns meses e preciso recuperar o atraso em muitas coisas.

Também acho que eu não sou um jogador ruim, mas me falta a maior parte da teoria avançada de suporte ou de jogar em geral, e eu estaria interessado em alguns bons recursos onde eu possa recuperar o atraso em tudo que é importante.

Atualmente estou em prata II (só joguei os jogos de promoção e nada mais), se é de alguma forma importante para a questão.

TL;DR: Quais são os melhores recursos relacionados a suporte?

killua544

Com uma rápida pesquisa no google., Estes são os 2 que eu encontrei e que pareciam relativamente decentes, é claro que muito disso será ultrapassado mas os princípios permanecem os mesmos.

Se você tiver alguma dúvida, fique à vontade para me enviar uma mensagem e eu vou ajudá-lo o melhor que posso.
} 
meio de League of Legends foi ampliado para a busca por relações em espaços presenciais. Na última Comic-Con? ${ }^{7}$, realizada em San Diego, a presença de estandes e cosplayers com a temática de League of Legends foi dominante nos espaços, colocando LoL no mesmo contexto que outros ícones da cultura popular jovem.

O jogador profissional de League of Legends, M.E.G, narra esse crescimento, e pontua a importância dos jogadores para esse desenvolvimento:

"...dei entrevistas para jornais [...] as pessoas queriam saber mais do jogo, da minha história, mas foram elas mesmas que espalharam essa história. No regional de Porto Alegre, eu nem estava jogando, mas as pessoas queriam tirar foto, pegar autógrafo. Todo mundo tem perguntas pra fazer, todo mundo quer tirar dúvidas, saber como jogar melhor. Se eu cresci, se fui visto, foi porque a comunidade me deu essa visibilidade." (M.E.G)

Durante o campeonato mundial de LoL em 2015, a comunidade no Reddit foi invadida pela propagação de tópicos que convidavam jogadores a participarem de eventos presenciais destinados a assistir os jogos coletivamente, compartilhando esses momentos com outros jogadores. Na figura 5, foram separados alguns exemplos de cidades na Alemanha, Holanda e Reino Unido que incentivaram jogadores a se reunirem presencialmente, para que estes pudessem acompanhar as semifinais e finais da competição juntos.

\section{Worlds Final event (Edinburgh, UK) \\ Worlds viewing party in Karlsruhe, Germany \\ Dutch viewing party, who's in?}

Figura 5: exemplo de movimentos independentes da comunidade ${ }^{8}$

Com a organização a cargo dos jogadores, vemos na figura 6 o convite para jogadores de Nova Iorque participarem de um evento com comidas personalizadas, camisetas temáticas e outras atrações. Entretanto, o que chama atenção é o incentivo dos autores dos tópicos para a replicação do evento em outros lugares, dando permissão para que as ideias fossem "roubadas" por outros jogadores que quisessem reproduzir os eventos em suas cidades.

\section{Hi Redditors looking improve your local League scene! We organized a Worlds Theater Party in Times Square - we teamed up with community members to bake poro cupcakes and design a t-shirt. Red Bull \& the local news stopped by to support! Steal our ideas and grow your scene. :)}

Figura 6 - movimento de organização coletiva ${ }^{9}$

\footnotetext{
7 Evento cultural que, inicialmente, abordava revistas em quadrinhos (comics), filmes e televisão, e com o passar dos anos começou a incluir alguns outros elementos da cultura pop como animes, brinquedos, videogames e livros de fantasia entre outros.

8 Evento final mundial (Edimburgo, Reino Unido)

Reunião para assistir o mundial, em Karlsruhe, Alemanha

Reunião holandesa para assistir o mundial, quem tem interesse?

${ }^{9}$ Oi redditors procurando melhorar a sua cena de League local! Organizamos uma reunião para assistir o mundial em Times Square - nos unimos com membros da comunidade para assar biscoitos poro e projetar uma camiseta. Red Bull e as notícias locais vieram para apoiar! Roube as nossas ideias e cresça sua cena. :)
} 
Em outro evento, na cidade de Los Angeles, a comunidade de LoL no Reddit foi convidada para assistir as partidas com jogadores profissionais de League of Legends. Dessa forma, buscava-se aproximar a comunidade e estimular a troca de conhecimentos entre jogadores profissionais e não profissionais de forma presencial, propiciando aos participantes outros modos de interagir com os experts, que não estivessem restritas a apenas assistir ou a torcer por eles em jogos - mas também a torcer com eles - podendo dividir experiências mais amplas de pertencimento à comunidade de League of Legends.

\section{Hey SoCal, League LA is inviting you to join us for our FREE World Finals Viewing Party with FREE SWAG ft. Voyboy, Lilypichu, BoxBox, Missyeru, Pro Teams, and MORE at the Dave \& Busters Arcadia!}

Figura 7 - integração entre iniciantes e experts. ${ }^{10}$

Nos Estados Unidos, League of Legends é considerado um esporte desde 2014. Esse reconhecimento fornece condições para que universidades possam criar clubes dedicados a LoL e oferecer bolsas de estudos para aqueles que, além de jogar, contribuam para a criação de conteúdos para o jogo, e possuam um bom desempenho escolar. Em 2015, o clube da universidade de Iowa convidou jogadores para assistirem aos jogos no campus com a possibilidade de participarem de sorteios e ganharem prêmios oficiais, fornecidos pela Riot Games.

\section{The University of Iowa League of Legends club invites you to it's Worlds Viewing party! \\ \$ 6 pontos 15 comentários enviados 6 dias ago by The_Purple_Salmor 5 to / $r$ /leagueoflegends}

on the 31st of October, the University of Iowa is having it's annual worlds viewing party!

Whether you go to the University or not you are welcome to come, and it will be a blast! All the information about address and time is in the link above, hope to see you there!

Edit: I forgot! there will also be PRIZES! Riot has given us things to give out at the event, and if you win the raffle, you could get cool league of legends stuff!

Figura 8: LoL surge na educação ${ }^{11}$

A valorização de iniciativas que partem dos integrantes da comunidade também costuma ser reforçada no sentido de demarcar a importância destes movimentos para a constituição do próprio espaços de afinidade. Nessa direção, poder analisar cada movimento como singular e relevante para o coletivo é uma característica destes espaços de afinidade, que se constituem como uma referência importante quando pensamos em culturas participativas. A comunidade de LoL, e outras comunidades de jogadores se formam diariamente nesta direção de criação conjunta, de compartilhamento de conhecimento e de abertura de possibilidades de ação para jogadores do mundo inteiro.

\footnotetext{
10 Oi SoCal, League LA está convidando você a se juntar a nós para a nossa reunião GRATUITA para assistir o mundial com FREE SWAG com Voyboy, Lilypichu, BoxBox, Missyeru, equipes profissionais, e MAIS no Dave \& Busters Arcadia!

${ }^{11} \mathrm{O}$ clube de League of Legends da Universidade de Iowa convida você para sua reunião para assistir o mundial! No dia 31 de outubro, a universidade de Iowa terá sua reunião anual para assistir o mundial. Você sendo aluno da universidade ou não, será bem vindo, e será um arraso! Todas as informações sobre data e horário está no link a seguir, espero ver vocês lá!

Edição: Eu esqueci! Lá também terão PRÊMIOS! Riot nos deu coisas para darmos durante o evento, e se você vencer a rifa,
} poderá ganhar coisas muito legais de league of legends. 


\section{Discurso Sobre Violência}

Ao buscar em redes sociais os relatos sobre League of Legends feitos por grupos de jogadores de outros games do mesmo gênero - como Dota e WoW -, alguns desses jogadores comentam a dificuldade de um jogador inexperiente se integrar a comunidade de LoL, considerada por eles como "tóxica", isto é, caracterizada por práticas consideradas desagregadoras, agressivas ou inadequadas, como ofensa virtual (ou cyberbulling), spam e trolling (FRAGOSO, 2015). Segundo os relatos, jogadores veteranos não teriam paciência com novos membros, pois estes não possuem tanto conhecimento prático quanto eles. Entretanto, observamos que comportamentos nesse sentido ocorrem majoritariamente dentro das partidas de jogo, quando uma derrota parece ser o desfecho mais provável. Ao conversar sobre as diferenças entre ações dos jogadores dentro e fora do jogo, M.E.G. fala sobre violência e ressalta que:

"Dentro do jogo, quando tu está com pessoas do mesmo nível, e tem um jogo bom, tu não vê ninguém ofendendo [...] o problema é quando o jogador não sabe nada, não entende como se movimentar, ou não sabe que tem que se proteger dos adversários. Fora do jogo o pessoal até topa ajudar, conversar, explicar um pouco, mas dentro do jogo não dá tempo, então o pessoal só manda "ficar na base escondido e não morrer" e, se segue morrendo, ai tem gente que manda longe mesmo. " (M.E.G)

A comunidade de jogadores e desenvolvedores de League of Legends estimula interessados no jogo a buscarem espaços de aprendizado sobre o jogo, mas durante uma partida o jogador pode encontrar dificuldades para se fazer compreender em suas dúvidas. Assim, se configura uma diferença nas relações dentro e fora do jogo. No jogo, os jogadores mais antigos mostramse menos receptivos a ensinar, preocupando-se mais com a disputa pela vitória. Isto pode sugerir a jogadores novatos que não há espaços para aprender. Acreditamos, entretanto, que, quando o jogador se insere nos espaços de discussão e aprendizado fora do jogo, ele não só encontra ajuda para aprimorar suas habilidades com campeões ou rotas específicas, como também pode vivenciar formas diferentes de se relacionar com o jogo em um ambiente em que a competição e o stress da busca pela vitória não constituem uma prioridade imediata para os demais participantes. Sugerimos que outros estudos possam ser produzidos para avaliar essa possível relação entre o caráter competitivo do jogo e o comportamento violento de alguns jogadores.

\section{Discussão}

A comunidade de League of Legends no Reddit reforça a cultura colaborativa, transformando consumidores em produtores de conteúdo, funcionando como uma plataforma em que cada usuário pode expressar suas opiniões, organizando formas de comunicação digital à distância e, ao mesmo tempo, possibilitando o envolvimento dos participantes em projetos realizados em localidades próximas, como em sua cidade ou país. Poder compartilhar uma vitória com jogadores de outros estados, torcer pela mesma equipe em campeonatos nacionais ou mundiais e conversar com desenvolvedores ou outros jogadores sobre as mudanças no jogo são exemplos de movimentos que cada vez mais transpõem a esfera digital em direção a uma participação que se constitui para além do anonimato.

Existe, entretanto, uma crítica recorrente sobre os jogos digitais, que os considera uma ferramenta de produção de violência e estimulação de comportamentos agressivos naqueles que os jogam. Em nosso estudo observamos dificuldades de comunicação durante as partidas, quando um jogador iniciante não compreende a linguagem específica utilizada por jogadores mais experientes, ou quando não apresenta um nível esperado de conhecimentos sobre o funcionamento do jogo - sua jogabilidade - o que pode refletir em interações agressivas. Ao analisarmos, contudo, espaços de afinidade em torno do jogo League of Legends - como o fórum Reddit - não observamos esse padrão de comportamento violento. Assim, acreditamos termos encontrado indícios para afirmar que mesmo que existam representações de violência (campeões lutando entre si, derrotando monstros, destruindo estruturas) e - em um contexto específico de 
partidas em que jogadores com níveis de conhecimentos muito discrepantes integram a mesma equipe - violência entre jogadores (ofensas, abandono a partidas ou performances propositalmente ineficientes), não há relação direta que indique que o jogo produza violência em espaços externos a ele. Caso essa relação fosse verdadeira, seria esperado que comportamentos violentos estivessem presentes também nos espaços de afinidade - como em fóruns de discussão online sobre o jogo -, pois estes têm uma participação intensa de jogadores que produzem ou que se defrontam com situações violentas durante algumas partidas. Acreditamos que, se não há uma transposição de comportamentos violentos para os espaços de afinidade em torno do jogo League of Legends, não é improvável que o mesmo ocorra para outras esferas da vida, fora do contexto dos jogos. Dessa forma, a existência de violência dentro do jogo não pode se configurar como um argumento para embasar a ideia de que os jogos produzem violência em outros contextos, pois aponta que a violência relacionada aos jogos não é reproduzida em situações externas a eles.

\section{Considerações Finais}

Estudar a experiência de extensas comunidades de jogadores com os jogos digitais possibilita produzir conhecimento sobre um campo que é permeado por discursos controversos, em especial, no que se refere à possibilidade dos mesmos produzirem comportamentos violentos. Abordamos o League of Legends, um jogo online de computador, como dispositivo de análise para discutir as performances de interação entre jogadores nos ambientes virtuais, por meio da constituição de espaços de afinidade em torno das experiências de jogo.

League of Legends é considerado uma referência importante para a compreensão das experiências de jogo em torno dos jogos online multijogadores, por ser muito popular dentro da cultura gamer. O desenvolvimento do jogo não se encerrou em sua publicação. Ele é constantemente atualizado com a participação de uma comunidade bastante ativa de jogadores que impulsionam o melhoramento do jogo, por meio de espaços de afinidade. Tais espaços promovem uma cultura participativa, que pode embasar estratégias potentes de produção de conhecimento coletivo proporcionando aos participantes a oportunidade de trabalharem em equipe e se sentirem encorajados a produzir conteúdos de forma autoral, a partir do compartilhamento de estratégias e habilidades desenvolvidas em suas performances de jogo com seus pares.

Ao analisarmos a participação dos jogadores em espaços de discussão periféricos ao jogo, observamos que as situações violentas envolvendo o LoL se limitavam à interação no ambiente projetado das partidas de jogo, não se fazendo presentes em outros espaços. Participando de espaços colaborativos que estimulam o estudo sobre determinado jogo - suas possibilidades e estratégias - os jovens acabam produzindo - mesmo em comunidades sobre um jogo que possa conter marcadores violentos - discussões que estimulam a produção de modos de subjetivação relacionados a convivência não violenta.

Reforçar o interesse nas experiências de aprendizagem presentes nos jogos digitais contribui com a compreensão de que os modos clássicos de metodologias de ensino, baseados em processos unilaterais de transmissão de conhecimento, não são exclusivos e que há outras relações possíveis entre sujeitos e produção de conhecimento, entendendo existir diferentes tipos de performances criando essas relações, assim como diferentes formas de constituir e habitar os espaços coletivos. Nessa direção, é importante poder afirmar a potência dos espaços de afinidade em torno dos jogos, uma vez que a multiplicidade de configurações e de possibilidades de participação produzidas nesses espaços ajudam a pensar outras formas coletivas de produção de conhecimento. 


\section{Referências}

ALVES, L. R. G. (2004). Game Over: Jogos Eletrônicos e Violência. Tese de Doutorado, Universidade Federal da Bahia, Salvador.

ARRIAGA, P., ESTEVES,F., MONTEIRO, M.B. (2007). Violência em jogos eletrônicos e reações emocionais a imagens da vida real: hipótese da dessensibilização. Percursos de investigação em psicologia social e organizacional v.2, p.119-143. Lisboa. Editora Colibri.

BARTLE, R. (2010). A Digital Culture, Play and Identity: A World of Warcraft Reader. Game Culture, 10(1). Disponível em: http://gamestudies.org/1001/articles/bartle

BAUM, C. (2012). Sobre o videogame e cognição Inventiva. Tese de Mestrado, Universidade do Rio Grande do Sul, Porto Alegre.

BLIZZARD ENTERTAINMENT Inc (1998). Starcraft. Blizzard, Irvine, California.

(2002). Warcraft III. Blizzard, Irvine, California.

(2004). World of Warcraft. Blizzard, Irvine, California.

DE PAULA, G. N. (2010). Caracterizando o videogame como novo letramento: uma proposta para a escola. Revista Educação \& Tecnologia. 15(1)

EUL. (2003). Defense of the Ancients.

FRAGOSO, (2015). "HUEHUEHUE I'm BR": Spam, Trolling and Griefing in online games. Revista Famecos. Porto Alegre, 22(3).

GAVILLON, P. Q. \& MARASHCIN, C. (2015). Políticas cognitivas, aprendizagem e videogames. Em Jogos eletrônicos, mobilidades e educações: trilhas em construção (Alves, L. e Nery, J. Orgs). p. 323-340.

GEE, J. P. (2003). What video games have to teach us about learning and literacy. New York: Palgrave/Macmillan.

(2010) Bons videojogos + boa aprendizagem: Colectânea de ensaios sobre os videojogos, a Aprendizagem e a Literacia. Edições Pedago.

JENKINS, H. (2006). Fans, Bloggers and gamers: exploring participatory culture. New York University Press.

(2009). Cultura da Convergência. São Paulo, Aleph.

MARASCHIN, C. \& BAUM, C. (2011) Explorando Arkaham Asylum: Sobre videogame e aprendizagem inventiva. Revista Pólis e Psique v1(2) p38-52.

RIOT GAMES (2013) Infográfico da comunidade. Riot Games Inc. Disponível em: http://na.leagueoflegends.com/en/community-infographic manifesto\#1

(2014) The Riot Manifesto. Riot Games Inc. Disponível em: http://www.riotgames.com/riot-

RIOT GAMES Inc. (2009) League of Legends. Riot Games. California, US.

SALEN, (2004) Rules of Play: Game Design Fundamentals. The MIT Press, Cambridge, Massachusetts.

SQUIRE, K. (2006) From content to context: videogames and designed experience. Educational researcher, v35 n8 p19-29.

(2011) Videogames and learning: teaching and participatory culture in digital age. Teachers college press, New York. 
STEINKUEHLER, C. (2006) Why Game (Culture) Studies Now? Games and Culture, 1(1), 97.

VOLK, P. (2016). League of Legends now boasts over 100 million monthly active players worldwide. The Rift Herald. Disponível em: http://www.riftherald.com/2016/9/13/12865314/monthly-lol-players-2016active-worldwide

Submetido para avaliação em 15 de setembro de 2016

Aprovado para publicação em 22 de março de 2017

\section{Jonathan Bernardes Golart}

Núcleo de Pesquisas em Ecologias e Políticas Cognitivas - Universidade Federal do Rio Grande do Sul UFRGS, Brasil, jo.golart@gmail.com

\section{Renata Fischer da Silveira Kroeff}

Núcleo de Pesquisas em Ecologias e Políticas Cognitivas - Programa de Pós-Graduação em Psicologia Social e Institucional - Universidade Federal do Rio Grande do Sul - UFRGS, Brasil, kroeff.re@gmail.com

\section{Póti Quartiero Gavillon}

Núcleo de Pesquisas em Ecologias e Políticas Cognitivas - Programa de Pós-Graduação em Psicologia Social e Institucional - Universidade Federal do Rio Grande do Sul - UFRGS, Brasil, poti.gav@gmail.com 